\title{
Imaginação e educação: repercussões das ideias de Espinosa no enfrentamento de questões contemporâneas
}

\section{Licenciada em Pedagogia pela Faculdade de Educação da Unicamp Ana Luiza Smolka} Professora doutora da Faculdade de Educação da Unicamp

\section{Resumo}

Este trabalho toma como disparador duas situações de sala de aula em que se questiona se a imaginação como gênero do conhecimento constitui uma ameaça ou uma possibilidade potencial do desenvolvimento humano. Para tanto, estudamos o prefácio e os dois primeiros capítulos do Tratado Teológico Político, o Tratado da Reforma da Inteligência, e a Ética de Espinosa. Nesse sentido buscamos compreender as possíveis repercussões do estudo do conceito espinosano de imaginação no âmbito educacional contemporâneo.

Palavras-chave: imaginação, conatus, política, questão ético-política.

\begin{abstract}
This study has as motivation two class situations where we ask whether imagination as a gender of knowledge is a threat or a potencial possibility to the human development. To study it, we use the texts of Spinoza: Tractatus Theologico-politicus or Theologico-Political Treatise (prefacy, first and second chapters), Tractatus de Intellectus Emendatione (or On the Improvement of the Understanding)., and The Ethics. In this sense, we attempt to understand the possible reverberations from the study of Spinoza's concept of imagination to the field of contemporary education.
\end{abstract}

Key-words: imagination, conatus, question politic-ethics. 
Trazer o pensamento de Espinosa (1632-1677), filósofo, matemático, polidor de lentes, excomungado pela comunidade judaica de Amsterdã no século XVII, para o âmbito da pesquisa em educação e Pedagogia contemporânea, mesmo que historicamente contextualizado, pode ser uma proposta um tanto audaciosa ${ }^{1}$. Esse artigo problematiza justamente a possibilidade do pensamento espinosano contribuir com as discussões atuais sobre educação. Como seria possível fazer dialogar a filosofia de um pensador do século XVII com o contexto atual? No que o pensamento espinosano é fecundo dentro das elaborações e pesquisas de educação de hoje? Os modos de Espinosa conceber o afeto, o desejo, a política e mais especificamente a imaginação, contribuem para analisar os diferentes modos de compreender os mesmos conceitos na contemporaneidade?

O interesse no estudo do conceito de imaginação no pensamento de Espinosa emerge de uma pesquisa anterior feita sobre as possíveis repercussões do pensamento de Espinosa sobre a elaboração do conceito de imaginação no pensamento de Vigotski (KUSUNOKI, 2011).

Nesse sentido, apresentamos a seguir duas situações ${ }^{2}$, vivenciadas em sala de aula, tomadas como lugares de inspiração e problematização do conceito de imaginação de Espinosa nas reflexões atuais da educação.

1. "Horton é uma ameaça. Ele faz as crianças usarem a imaginação." (Fala da mãe canguru no filme Horton, e o mundo dos Quem)

Hoje a sala assistiu ao filme "Horton, e o mundo dos Quem". Ele trata de um elefante que consegue conversar com a população (em um outro mundo microscópico) que vive em uma simples florzinha delicada. O conflito inicia quando a sociedade da floresta começa a se incomodar com Horton falando com a flor, pois todas as "crianças-animais" desejam também ter uma florzinha e um mundo microscópico para conversar. Assim, a mãe canguru

\footnotetext{
${ }^{1}$ Desde já podemos colocar as questões que nos aparecem quando vamos pensar Espinosa e a educação atual: quais conceitos usar quando pensamos em educação? Desenvolvimento humano ou liberdade? Emoção ou afeto? Conduta da razão?

${ }^{2}$ As situações foram registradas em vídeo-gravações que podem ser encontradas no arquivo do grupo de Pesquisa Pensamento e Linguagem da Faculdade de Educação da Unicamp. Elas foram feitas no $2^{\circ}$ ano do ensino fundamental de uma escola pública municipal de ensino fundamental.
} 
organiza um levante para que a flor seja destruída e o elefante pare de alimentar a imaginação das crianças com asneiras. (Diário de Campo, 23-092009).

2. No dia 16 de junho de 2010 , a professora Isnary subiu em uma cadeira e colocou um mapa plano grande na parede da sala, onde fica a lousa. Era uma aula de geografia. Ela tinha também em suas mãos um globo terrestre. Tomando como um disparador da aula a copa do mundo, ela vai mostrando no mapa os países que os alunos afirmam estarem participando. Para tanto, ela recorda do filme "Madagascar" que os alunos viram em sala de aula. A seguir, a transcrição:

Prof.: Quem lembra do filme Madagascar?

Crianças: Eu, eu !!! (Dizem em coro levantando a mão).

Prof.: Os bichinhos saíram daqui dos EUA, Nova York, e foram de naviozinho até Madagascar. (Indicando o caminho no globo em sua mão).

Crianças: Existe, Professora, existe?!!!

Prof.: Existe, existe sim. (Com um sorriso e com a cabeça afirmando que sim).

Começa um grande agito na classe, todos começam a conversar surpreendidos.

Prof.: Oh, Oh, ou a gente combina que ergue a mão para falar e todo mundo fala ou então não fala ninguém, só a Isnary.

Jorge levanta a mão.

Prof.: Vamos, fala Jorge.

Jorge: Os bichinhos do Madagascar existe?!

Prof.: Os bichos existem. Aquele lá é um desenho que foi criado, mas os animais e Madagascar existe. A história foi inventada, de pegar os bichos do zoológico e levar lá para Madagascar. Mas existe, existe Madagascar e existe o zoológico e existe os animais.

Tatiane: Professora, professora! (levanta a mão impaciente para falar)

Prof.: Fala Tatiane.

Tatiane: Mas eles não falam, né? (empolgada).

(Excerto transcrito de aula vídeogravada em 16-06-2010)

Na primeira situação, o conteúdo do filme é tomado como objeto de pesquisa para pensar o conceito de imaginação no pensamento espinosano. Tomando como argumento a concepção de Espinosa sobre a imaginação como um modo de percepção que deve ser superado, problematizamos: Qual a ameaça da imaginação para Espinosa em relação à ameaça que ela

\footnotetext{
${ }^{3}$ Situação registrada em vídeo-gravação, pode ser encontrada no arquivo do grupo de Pesquisa pensamento e Linguagem da Faculdade de Educação da Unicamp.
} 
proporciona para a mãe canguru do filme? Quais as repercussões desse pensamento para se pensar em educação atualmente?

$\mathrm{Na}$ segunda, analisando as condições de sala de aula e os discursos entre professor e alunos, nos questionamos: o que pode significar a ansiedade das crianças por descobrir se os personagens do filme existem? O que há de positividade e possibilidade no exercício da imaginação neste caso? O trabalho de imaginação dos alunos, enquanto amam - no sentido espinosano: alegria causada pela ideia de uma causa exterior - os personagens de "Madagascar" e, por isso, querem saber ansiosamente se eles existem, constitui uma possibilidade educativa nesta situação ou uma ameaça ao próprio conhecimento pela conduta da razão? O que privilegiar nesta situação, o desejo, o amor das crianças ou a eliminação da imaginação?

Dentro deste contexto, nos indagamos quais as contribuições do pensamento de Espinosa para tratar dessas questões. Para tanto, utilizamos o prefácio, capítulos 1 e 2 do Tratado Teológico Político, o Tratado da Reforma da Inteligência, e a obra mestra, a Ética de Espinosa.

Os estudos sobre o tema nos levam a compreender e destacar a dinâmica da relação da imaginação com a política, o afeto e o conatus.

\section{Imaginação e ameaça.}

O que constitui a ameaça da imaginação para Espinosa?

Analisando o filme "Horton e o mundo dos Quem", nos indagamos o que representa a ameaça da imaginação. Horton e sua flor são uma ameaça à educação das crianças para a mãe Canguru, porque eles instigam o uso de suas imaginações, questionando a realidade e a sociedade em que vivem. Destruir a flor é símbolo da eliminação da imaginação, da criação humana e dos questionamentos internos e externos que este processo gera no sujeito.

E para Espinosa? Qual é a ameaça que o uso da imaginação constitui? 
Para Espinosa, no TRI, a imaginação é definida como o primeiro e o segundo modo de percepção que tem por objeto uma coisa considerada como existente originando as ideias fictícias, falsas e duvidosas (ideias confusas, vagas que não atingem a essência causal das coisas e não dependem da força e da natureza do entendimento). No livro II da Ética, ela é compreendida como o primeiro gênero do conhecimento, sendo definida como as afecções ${ }^{4}$ ou as ideias das afecções do corpo que representa o corpo exterior como estando presente (P17, Esc.). Para Espinosa,

[...] a mente não erra por imaginar, mas apenas enquanto é considerada como privada da ideia que exclui a existência das coisas que ela imagina como the estando presentes. Pois, se a mente, quando imagina coisas inexistentes como se lhe estivessem presentes, soubesse ao mesmo tempo, que essas coisas realmente não existem, ela certamente atribuiria essa potência de imaginar não a um defeito de sua natureza, mas a uma virtude, sobretudo se essa faculdade de imaginar dependesse exclusivamente de sua natureza, isto é (pela def. 7 da P.1), se ela fosse livre. (ESPINOSA, 2008, p.111, P17, Esc. $)^{5}$.

Tanto no TRI, no TTP como na Ética o autor critica em alguma medida o uso da imaginação sem a intervenção da razão ou segundo gênero do conhecimento. Isto porque o filósofo está em busca do modo de percepção ou gênero do conhecimento que mais convenha ao homem para desfrutar da felicidade, na busca do verdadeiro bem-comum e, sendo assim, a imaginação não pode ser o melhor gênero do conhecimento neste caso, pois:

1) No $T R I$, ela é definida como sensação fortuita, solta, que não nasce da própria força da mente, mas de causas externas, conforme o corpo é afetado por diversos movimentos, tornando a mente passiva, formando

\footnotetext{
${ }^{4}$ Afecção para Espinosa é modificação de um corpo causado pelo encontro com outro corpo.

${ }^{5}$ Espinosa será citado neste trabalho nas formas: obra, proposição, escólio (caso haja) ou demonstração quando se tratar da Ética. Depois, a citação segue como a norma da ABNT: autor, ano e página.
} 
ideias falsas, fictícias e duvidosas que dificultam a própria execução do método na busca pela ideia verdadeira;

2) No prefácio e capítulos 1 e 2 do $T T P^{6}$, analisando as profecias da Escritura, a imaginação é o meio pelo qual os profetas divulgavam as suas revelações, sendo elas compostas por imagens e figuras não reais, ligadas aos seus contextos, moralismos e temperamentos particulares, estando predominantemente longe da verdade e da compreensão das coisas pela conduta da razão; além disso, a imaginação, somada ao medo, alimenta a superstição religiosa que gera, consequentemente, a relação de dominação humana;

3) No apêndice do livro I da Ética, ela afirma a crença em um Deus antropomórfico e finalista que subjuga os homens ${ }^{7}$. A imaginação é o primeiro gênero do conhecimento humano em que os sentidos representam as coisas singulares de forma mutilada e confusa sem a ordem do intelecto e/ou que se formam pelos signos das palavras (Ética II, P40, Esc. $)^{8}$; sendo a única causa de falsidade (Ética II, P41), não envolvendo a distinção entre o verdadeiro e o falso (Ética II, P42), considerando as coisas como contingentes, com respeito ao passado ou ao futuro (Ética II, P44, Corol.). Ela diz respeito à concepção atual das coisas em um tempo e local

\footnotetext{
${ }^{6}$ O TTP tem como principal objetivo separar a teologia da filosofia, uma vez que os profetas não divulgam o conhecimento natural, mas interpretações que asseguram sua autoridade, apoiando-se em revelações divinas e testemunhos interiores, e que os filósofos sustentam-se unicamente no seu direito natural, guiando-se pela conduta de sua própria razão.

${ }^{7}$ No apêndice 1, da Ética I, Espinosa busca retomar os conceitos de Deus já explicados na obra para se dedicar aos objetivos da escrita da mesma: a) afastar os preconceitos que possam impedir a compreensão de Deus e b) entender porque a maioria dos homens abraça esse preconceito (parágrafo 1). Uma vez entendendo que todos os homens nascem ignorantes das causas das coisas (inclusive das suas volições) e buscam o que lhes é útil, Espinosa compreende porque eles produzem o preconceito do Deus antropomórfico e finalista. Para ele, a natureza não tem nenhum fim que tenha sido pré-fixado e as causas finais não passam de ficções humanas. Assim, a doutrina finalista inverte totalmente a natureza, pois considera o que é efeito como causa, inverte o que é perfeito em imperfeito etc. Como diz Espinosa: "Cada um julga as coisas de acordo com a disposição de seu cérebro, ou melhor, toma as afecções de sua imaginação pelas próprias coisas" (ESPINOSA, 2008, p. 71). A imaginação cria entes que não indicam coisas da natureza e essa é a causa da formação do imaginário religioso que produz homens medrosos e supersticiosos, prontos para serem subjugados pelas autoridades. 8
} 
determinado, e não consegue compreender a dimensão eterna de Deus e de si mesmo como causa de si (Ética V, P29, P32). Em suma, somente através da imaginação, o homem não consegue conceber a totalidade e a visão universal das coisas, não podendo atingir a essência particular das coisas, mas sim sua existência em ato. Por isso, na escolha do melhor gênero do conhecimento para o exercício de uma vida ética e comum, Espinosa demonstra, à maneira dos geômetras, que o terceiro gênero - a intuição - é a melhor opção, sem negar a possibilidade da passagem do primeiro ao segundo gênero do conhecimento e do segundo ao terceiro.

É importante ressaltar que, em si, a imaginação não é um empecilho ao verdadeiro conhecimento. Como afirma o escólio da proposição 17 do livro II da Ética, citado acima, ela só leva ao erro humano à medida que quem imagina considera como existente aquilo que não é. Ou seja, se a pessoa que imagina sabe que imagina e que os produtos da sua imaginação não estão presentes, a imaginação pode ser considerada uma virtude, à medida que ela dependerá exclusivamente da potência da mente da pessoa que imagina. Além disso, a imaginação é um modo de percepção/gênero do conhecimento da existência das coisas através da transição de potência do corpo - o afeto - que guarda as marcas do corpo modificante no corpo modificado, tendo a percepção da coisa em ato, no tempo presente. Sendo assim, ela pode ser considerada também uma virtude enquanto possibilita a infinidade de modos de afeç̧ão do corpo e um problema epistemológico enquanto o corpo não tem consciência de sua própria capacidade de afetar e ser afetado, podendo trazer o padecimento ao corpo afetado que considera presente coisas que não estão.

A imaginação entra no pensamento espinosano como conhecimento que pode alcançar a liberdade humana de pensar, uma vez sendo alimentada por imagens de coisas que aumentam a sua potência de agir, vinculando cada vez mais à existência do corpo o aumento de sua própria potência e se desvinculando, simultaneamente, da ideia de causas exteriores aos afetos surgidos (livro V da Ética). Assim, aumenta-se a capacidade de percepção 
humana, de modo que o corpo em questão possui mais aspectos em comum com outros corpos, mais possibilidades de afetar e ser afetado.

Ora, se a imaginação em si não constitui uma ameaça ao conhecimento adequado, podemos afirmar que existe alguma outra ameaça da imaginação no pensamento de Espinosa?

A maior crítica de Espinosa à imaginação provém da realidade político-religiosa de sua época: a constituição de um imaginário religioso que alimenta a superstição, o medo e a crença cega na religião, a fim de manter o poder e o autoritarismo da Igreja. Encontramos tais afirmações do filósofo principalmente no prefácio do TTP e no apêndice da Ética I. Espinosa era filho de judeus portugueses refugiados na Holanda pela perseguição religiosa da época, onde participava da comunidade judaica de Amsterdã até ser excomungado em 1656. Como afirma Chauí (2005), a comunidade detinha uma forte divisão religiosa e teológica (fundamentalistas tradicionalistas, deístas racionalistas, talmudistas e cabalistas místicos) que dominava divergências sociais e políticas. Assim, os conflitos sociais, políticos e econômicos sempre apareciam sob a forma de conflitos religiosos. É nesse contexto, que o filósofo se dedicou a pensar sobre a liberdade humana, uma vida sem preconceitos religiosos, que pudesse atingir a paz social e a liberdade de escolha de cada um na busca de um verdadeiro bem-comum entre os homens.

Podemos afirmar que no pensamento de Espinosa o sentido de ameaça da imaginação aparece à medida que ela é o único modo de percepção das coisas, um modo de percepção vago, que não compreende as coisas por suas causas essenciais, podendo sustentar e gerar facilmente a superstição, principalmente quando somada ao medo ${ }^{9}$, colocando os homens em relação de subordinação.

\footnotetext{
${ }^{9}$ O medo é uma "tristeza instável, nascida da imagem de uma coisa duvidosa" (Espinosa, 1979, p. 187), ou como a Ética III define, uma tristeza instável surgida da ideia de uma coisa futura ou passada, de cuja realização temos dúvida. É uma flutuação de ânimo à medida que surge de dois afetos contrários (amor e ódio) e sempre é acompanhada da esperança, uma alegria instável surgida da ideia de uma coisa futura ou passada, de cuja realização temos dúvida.
} 
Tanto no filme, como no pensamento de Espinosa, a imaginação é uma ameaça. No filme, a ameaça é a subversão e no pensamento de Espinosa é a submissão. Em ambos a ameaça envolve o conflito éticopolítico e as relações de poder na sociedade. Essa é uma reflexão pertinente à contemporaneidade no campo da educação - uma questão atemporal que resiste até hoje. A diferença é que para Espinosa, a imaginação é a capacidade humana de receber impressões, ideia das imagens oriundas das afecções dos corpos que se forma vagamente, sem passar pela conduta da razão. Já no filme, a imaginação representa a possibilidade de criação do novo, a transformação.

Concluindo, as resultantes submissão e subversão nos abrem novas perspectivas para analisar a seguir a segunda situação vivenciada em sala de aula.

\section{Imaginação, afeto e conhecimento}

Retomando a situação exposta em sala de aula, destacamos o objetivo primeiro da professora ao falar sobre a África, a Copa do Mundo, o filme "Madagascar" e o mapa Mundi: o conteúdo de Geografia. Entretanto, como nos mostra a transcrição, o desejo das crianças de tornarem possível a existência dos personagens do filme desloca o foco da professora. A imaginação e, consequentemente, a memória, o afeto e o desejo das crianças aparecem como ameaça ao seu planejamento de aula.

Neste sentido, indagamos quais as repercussões do exercício da imaginação das crianças nas relações de sala de aula nesta situação especifica. Do que falamos quando tratamos de imaginação? Uma vez que compreendemos que a imaginação em si não é um empecilho ao exercício da vida ética para Espinosa, o que haveria de positividade e possibilidade no exercício da imaginação neste caso?

Como já vimos anteriormente, a imaginação é um modo de percepção, um gênero do conhecimento da existência das coisas exteriores através das imagens das afecções ou das próprias afecções resultantes dos encontros dos 
corpos. Dessas afecções, surgem os afetos - transições da potência de agir do corpo para um estado mais alto ou mais baixo e vice-versa - que tornam o corpo mais passivo ou ativo. É através da imaginação que um corpo exterior pode ser concebido como existente em ato e, por isso, a mente pode conhecer seu próprio corpo (seu objeto) pelas ideias das afecções do mesmo. Pela proposição 23 da parte II, temos:

A mente não conhece a si mesma senão enquanto percebe as ideias das afecções do corpo, pois o conhecimento dessas ideias envolve necessariamente o conhecimento da mente uma vez que a natureza do corpo humano está em concordância com a natureza da mente. (ESPINOSA, 2008, p.117).

Conforme a proposição 9 do livro III da Ética, a mente sempre está consciente de seu esforço em perseverar em seu ser por meio das ideias das afecções do corpo. Essa proposição explica a relação íntima entre conatus, afeto e imaginação. A imaginação opera através do afeto, gera transição de potência do corpo, guardando as marcas dessas modificações corporais que, necessariamente, mudam o estado presente do corpo - seu conatus. Para Espinosa, o conatus é o impulso de preservação na existência, é o próprio apetite/desejo, a própria essência humana, dinâmica e variável. É o princípio de vida de todos os seres, é a essência atual do corpo e se desenvolve ao longo da vida, conforme sua produção e em função dos afetos. As decisões da mente são os próprios apetites humanos que variam de acordo com a disposição do corpo, ou seja, cada um regula tudo de acordo com seu próprio afeto e desejo.

Tomando em consideração a realidade ontológica e afetiva da imaginação, em que o homem se esforça o quanto pode por imaginar aquilo que aumenta a sua potência de agir, (P12 e P13, livro III da Ética), Espinosa afirma nas proposições 25 e 26 da parte III da Ética, que é próprio do homem se esforçar por afirmar de nós e da coisa amada tudo o que a nós e ela imaginamos afetar de alegria. Mesmo não atingindo a essência da coisa, ou seja, sem apelar ao intelecto, esse esforço aumenta a potência de agir do 
homem. E é por isso que podemos explicar a potência do exercício da imaginação dos personagens nesta situação transcrita: imaginar a existência deles é o próprio esforço (conatus) das crianças de aumentarem a sua potência de agir - alegria. A possibilidade de existência dos bichos mobiliza as crianças ao conhecimento. $\mathrm{O}$ desejo pela possibilidade deles falarem aumenta suas potências de agir, gera alegria, ansiedade pelo conhecimento e até desloca o conteúdo principal da aula.

Por mais que as crianças, neste caso, não usem a conduta da razão para pensar e agir, podemos afirmar que a imaginação ainda sim é positiva para seu processo de desenvolvimento, pois aumenta e reafirma a sua própria potência.

\section{Conclusão}

O conceito de imaginação para Espinosa se insere em seu contexto histórico cultural: contexto de dominação teológica-política em que o filósofo prioriza a liberdade de pensamento. Sobretudo, Espinosa busca essa liberdade na vinculação das ações humanas a princípios corretos de viver de acordo com a potência de cada corpo - distante de dogmas e relações autoritárias de dominação.

A partir da análise das situações em sala de aula, podemos concluir que há pelo menos dois elementos do pensamento de Espinosa que ainda resistem nas discussões atuais sobre educação: a questão ético-política e os conceitos de afeto e de conatus (como impulso de preservação na existência). Retomando as questões iniciais deste artigo que problematizava a possibilidade de fazer dialogar a filosofia de um pensador do século XVII com o contexto atual, concluímos que esses dois aspectos analisados sobre a imaginação no pensamento de Espinosa transcendem o tempo, resistindo nas discussões atuais porque são problemas do drama da existência humana: relações de poder, afeto, desejo, variação de potência. As duas situações empíricas expostas nos trazem por excelência a contemporaneidade e a problematização da educação. Concluímos que pensar essas situações pela 
imaginação relacionando-as ao afeto, ao conatus e à questão ético-político ainda faz sentido hoje. Cabe destacar a relevância de um estudo mais aprofundado e extenso sobre Espinosa, a imaginação e a educação nas próximas pesquisas sobre o tema.

\section{Referências bibliográficas}

ESPINOSA, B. Tratado Teológico-Político. Lisboa: Imprensa Nacional, 1988a. Série Estudos Gerais. Notas, Tradução, introdução D. P. Aurélio.

. Tratado da Reforma da Inteligência. Tradução e notas de Lívio Teixeira. São Paulo: Martins Fontes, 2004.

KUSUNOKI, R. M. O problema da imaginação: Espinosa e Vigotski. 2011. 101 p. Trabalho de Conclusão de Curso em Pedagogia - Faculdade de Educação da UNICAMP.

SPINOZA, B. Ética. Tradução Tomaz Tadeu. Belo Horizonte: Autêntica, 2008. 